\title{
AVALIAÇÃO COMO CATEGORIA: \\ ELEMENTOS PARA UMA DISCUSSÃO
}

DOI: $105902 / 0102830811298$

Data de Submissão: 07/11/2013 Data de Aceite: 02/09/2014

\author{
Vicente Calheiros \\ Universidade Federal de Santa Maria \\ vicocalheiros@gmail.com \\ Maristela da Silva Souza \\ Universidade Federal de Santa Maria \\ maristeladasilvasouza@yahoo.com.br
}

RESUMO: O objetivo deste estudo é estabelecer reflexões a respeito da organização do trabalho pedagógico, centrando atenção no movimento existente entre os pares dialéticos "objetivo-avaliação" e "conteúdo-método" a fim de pontuar a centralidade da categoria avaliação. Para fundamentar os argumentos, faz-se um exame dos elementos referentes ao desenvolvimento do processo histórico, fundamentalmente no campo educacional. Cremos ser necessário o aprofundamento da análise desta categoria, para que se possa, entre outros aspectos, instrumentalizar a prática pedagógica.

Palavras-chave: Avaliação. Educação Física. Escola. Organização do Trabalho Pedagógico. 


\section{Introdução}

Avaliar é uma palavra, uma expressão, que não cabe em si mesma frente a suas múltiplas determinações. Seu significado imediato diz respeito à atribuição de valor a algo, ou alguém emitir juízos de valor (MACHADO, 2000). Entretanto, temos clareza de que este significado é histórico, pois responde às múltiplas determinações do seu tempo, sofrendo com as distintas transformações da base material da sociedade ${ }^{1}$. Sendo assim, a complexidade desta categoria remete à necessidade de aprofundar nossas observações, visto que a cada momento percebemos novas relações que podem ser estabelecidas frente às constantes mediações existentes entre a avaliação, a escola e a sociedade.

Entendemos que a busca pela compreensão das relações que se estabelecem a partir da avaliação deve estar centrada na análise das relações entre a organização do trabalho pedagógico e suas mediações com o mundo do trabalho. Essa posição se justifica pelo fato de que, se não compreendemos a categoria trabalho e suas múltiplas determinações no modo de produção capitalista, não alcançaremos a compreensão do trabalho pedagógico na escola e, consequentemente, na Educação Física (TAFFAREL, 2010).

Nossa perspectiva está centrada no Materialismo Histórico Dialético, entendendo-o como concepção de mundo, método de análise da realidade e práxis transformadora. Assumimos esse referencial pelo seu caráter prático, pelo fato de a teoria depender da prática, de nela se basear e, por isso, dela estar a serviço. A importância de estarmos atentos para o movimento entre a avaliação, a escola e o modo de produção capitalista, entre a prática e a teoria, se coloca no sentido de que a realidade é dinâmica, mas contraditória, sendo fundamental observarmos um objeto por diferentes ângulos, diferentes pontos, a fim de perceber seu movimento nos determinantes existentes no contexto social.

Deve-se compreender de que forma os determinantes do modo de produção capitalista interferem na educação e na escola, para que possamos, assim, entender o que é e para quê, realmente, serve a avaliação. Frente a esta constatação, emerge a seguinte questão: como se manifestam tais determinantes? Podemos, por ora, segundo dados de 2012, afirmar que no Brasil existem 159 mil escolas de Ensino Fundamental. Destas, 126,5 mil

\footnotetext{
${ }^{1}$ Para mais informações a respeito de transformações do entendimento da avaliação ao longo do processo histórico, ver em: LIMA, Marcos Antonio Martins. Pantometria, psicometria, docimologia e avaliação científica: uma trajetória histórica para a avaliação educacional até a era contemporânea. In: Marcos Antonio Martins Lima e Marcos Marinelli [orgs.]. Epistemologias e metodologias para a avaliação educacional: múltiplas visões e abordagens. Fortaleza: UFC, 2010, p.83-126.
} 
(80\%) não têm acesso a internet; 115 mil (73\%) não têm biblioteca; 21,5 mil (14\%) não têm energia elétrica; 11 mil (8\%) não têm banheiros (INEP/MEC, 2012, FRIZZO, 2012, p. 16). O conjunto dos problemas estruturais das escolas brasileiras de Ensino Fundamental que apontamos é menos extenso do que se apresenta na realidade; porém, acreditamos que ela (a realidade) já responde à nossa pergunta. Dessa forma, a construção de um posicionamento teórico deve levar em conta esses elementos, principalmente quando se discute a categoria avaliação. Para além destas questões, percebemos seus reflexos na forma como os professores trabalham, constatada aí uma clara precarização de suas condições de trabalho. Não temos dúvida de que estas condições interferem gravemente no trabalho pedagógico e, consequentemente, na avaliação. Temos este entendimento pelo fato de que nossas análises não partem, de acordo com Marx e Engels (2009),

[...] daquilo que os homens dizem, imaginam ou se representam, e também não dos homens narrados, pensados, imaginados, representados, para daí se chegar aos homens em carne e osso: parte-se dos homens realmente ativos, e com base no seu processo real de vida apresenta-se também o desenvolvimento dos reflexos e ecos ideológicos desse processo de vida (MARX \& ENGELS, 2009, p.31).

Feitas estas considerações, acreditamos termos alcançado condições de avançar no debate, tendo a clareza teórica do nosso ponto de partida, do local a partir de onde construímos nossas análises.

\section{A Organização do Trabalho Pedagógico: breves apontamentos}

A necessidade de se analisar os elementos que extrapolam o âmbito escolar se coloca no fato de que a avaliação sofre influências de múltiplas determinações; por isso, afirmamos a necessidade de se empreenderem novos estudos que, segundo Silva (2010), estabeleçam as relações e os nexos entre a avaliação, a escola e o modo de produção capitalista, procurando superar o reducionismo técnico que omite o estudo dos amplos significados que se escondem nessa prática, e que acabam por negar as relações/interesses de classe que se estabelecem entre a ciência e a sociedade, visto que a primeira é produto da segunda. Nos limites desta análise, os questionamentos giram em torno das questões técnicas e não estabelecem a fundamental articulação entre teoria e prática. Por não relacionar a educação 
com a realidade, entendida como processo histórico e não um fim em si mesmo, as análises permanecem no âmbito de "como" (relacionando aos diversos instrumentos avaliativos) e "quando" avaliar, permanecendo no exame de como construir uma forma adequada para se avaliar alunos. Em momento algum se questiona por que se avalia, nem ao menos se questiona a forma de avaliação e sua relação com o modelo de escola.

Acreditamos que a compreensão da realidade parte do estudo de sua historicidade e, como afirma Marx (2003, p.7), "os homens fazem a sua própria história, mas não a fazem como querem; não a fazem sob circunstâncias de sua escolha, e sim sob aquelas com que se defrontam diretamente, legadas e transmitidas pelo passado".

Diante de tais afirmações surgem, portanto, três questões: 1) "O que são estas múltiplas determinações?"; 2) "O que é o trabalho pedagógico²?"; e 3) "Quais as categorias que o compõem?". Em relação à primeira questão é preciso explicitar que não entendemos o termo "determinação" no sentido de ser algo pronto, imutável, já determinado, que não tenha condições de ser transformado. Se fizéssemos isso, estaríamos negando os fundamentos da dialética materialista. Essa expressão diz respeito aos distintos elementos da realidade, ou seja, às determinações (Projeto Político Pedagógico, escola, educação, sociedade, interesses de classes em disputa) que influenciam/ determinam a forma, o modo como se apresenta a categoria avaliação neste momento, podendo ela se apresentar de outras formas a partir do constante movimento existente na sociedade, no qual um elemento pode ser de grande importância em um dado momento e, em outro, não ter importância alguma.

A respeito da segunda pergunta valemo-nos de Frizzo (2008, p.06) ao afirmar que a concepção de trabalho pedagógico faz referência "[...] a uma noção ampliada de trabalho desenvolvido pelo professor na escola e suas possibilidades de articulação entre a macroestrutura sócio-política e o cotidiano da docência nos espaços escolares", estando dessa forma na dependência dos interesses/objetivos do capital junto à educação.

Entendemos que o trabalho pedagógico caracteriza-se como trabalho humano e, estando articulado ao processo de trabalho capitalista, tem sua finalidade no "disciplinamento para a vida social produtiva, em conformidade com as especificidades que os processos de

\footnotetext{
${ }^{2}$ Neste trabalho não iremos abordar a questão da categoria trabalho, sendo esta fundamental para a análise da realidade na perspectiva centrada no Materialismo Histórico Dialético. Entretanto, entendemos que para este estudo ela não se faz necessária, visto que nosso interesse é o debate sobre a categoria "avaliação" e seus principais determinantes, e não o de apresentar profundamente toda a discussão de base que sustenta nossos argumentos.
} 
produção, em decorrência do desenvolvimento das forças produtivas, vão assumindo [...]" (FRIZZO, 2008, p.11) e, subordinando-se à esfera da produção, o professor se insere na linha de montagem.

Analisando a terceira questão, afirmamos que, para compreender a categoria avaliação precisamos estabelecer, também, as relações desta com as demais categorias que compõem a organização do trabalho pedagógico, sendo os pares dialéticos objetivo/ avaliação, conteúdo/método (FREITAS, 1995) essenciais para estabelecer os nexos entre a educação e o modo de produção capitalista, visto que o modo como a educação é organizada atualmente reflete os interesses deste processo de produção. Para tornarmos mais claras nossas críticas, faremos alguns apontamentos, demonstrando como a escola assume e perpetua o modo de produção capitalista.

A escola, como hoje a conhecemos, é a expressão das relações de um determinado momento histórico, i.e., aquele em que, entre os Séc. XV e XVI, a classe social burguesa se consolidava como hegemônica e, para tal, necessitou dessa instituição para concretizar seus interesses (ENGUITA, 1989). Sendo assim, entendemos que a escola não se coloca fora da luta de classe, pois - estando interpelada pelos interesses da burguesia e dos trabalhadores em condições desiguais - esta instituição é de fundamental importância. Não estando isenta desses determinantes, responde efetivamente a eles sendo, para Pistrak (2000), uma arma nas mãos das classes dirigentes. Para Freitas (2010, p.155), "as classes dominantes necessitavam de uma instituição que monopolizasse a formação da juventude, colocando-a em sintonia com a sociedade que a cerca - como consumidores e como força de trabalho, submetida à lógica do capital”. Cabe colocar que a avaliação é trabalhada fundamentalmente (mas não exclusivamente) dentro da sala de aula e este espaço, de acordo com Enguita (1989), foi reorganizado de tal forma que se converteu no local apropriado para as crianças e os jovens acostumarem-se às relações sociais do processo de produção capitalista, transformando-se no espaço institucional adequado para preparar crianças e jovens para o trabalho. Não basta apenas dirigir um olhar crítico para a avaliação (assim como para as demais relações escolares), porque ela não se esgota em sala de aula; faz-se necessário, sim, perceber este movimento que se estabelece, nos marcos deste debate, entre o singular (avaliação), o particular (escola) 
e o geral ${ }^{3}$ (modo de produção capitalista). De acordo com Pistrak (2009, p.79) "há um conteúdo na forma como a escola se organiza para vivenciar as relações de poder postas em seu interior a mando do sistema social vigente", ou seja, o modo como as relações se concretizam, a partir da organização do trabalho pedagógico, é a mesma forma que a escola assume e se articula dentro do modo de produção capitalista.

\section{A Centralidade da Avaliação e seu Caráter Pedagógico}

Entendemos que a avaliação é a categoria central para que possamos compreender os reais objetivos da educação e da escola, sendo esta a encarnação da função social capitalista para a educação (ESCOBAR, 1997). Por isso discordamos da afirmação de Rozengardt (2008, p.41) de que a avaliação é “[...] uma prática entre outras práticas”, pois, entendê-la desse ponto de vista, coloca-a no mesmo lugar que as demais (práticas), configurando-se aí um equívoco teórico. A avaliação modula o processo, pois este é construído a partir da constituição dos objetivos, e estes estão - como constataremos adiante - na dependência da categoria avaliação, visto que nenhum elemento do trabalho pedagógico pode ser trabalhado de forma separada, pois eles se relacionam no movimento do real, necessitando um do outro para ser concretizado. Para Freitas (1995, p.144):

Alguns pedagogos têm colocado ênfase na categoria conteúdo/método. Isso foi importante no momento em que as correntes libertárias diminuíram o papel destes no interior da escola. Hoje, no entanto, é preciso que reexaminemos esse enfoque, não para retirar a importância dos conteúdos, mas para chamar a atenção para a posição de dependência em que estes se encontram em relação aos objetivos/ avaliação da escola. Quando se enfatizam os conteúdos escolares, os neoliberais fazem coro, imediatamente. Tal postura é compreensível na medida em que a preocupação com o conteúdo/método [...], oculta e retira o debate crítico do campo dos objetivos/avaliação da escola [...]. (grifos nossos).

Ao compreendermos que a avaliação é a categoria que modula as demais, isso nos afasta de uma leitura mecânica e pragmática que, fundamentalmente, não esclarece que o professor a constrói para além da sala de aula, desde o momento em que entra na escola até o momento em que vai para casa, e não apenas quando aplica uma prova ou um trabalho.

\footnotetext{
${ }^{3}$ Para Lukács (1968, p.106), "a aproximação dialética no conhecimento da singularidade não pode ocorrer separadamente das suas múltiplas relações com a particularidade e com a universalidade". Trazemos esta passagem para firmar nossa posição de que analisar a avaliação pela avaliação torna a discussão vazia, estéril.
} 
Nos limites dessa análise que criticamos, o entendimento de avaliação predominante é o de que esta implica apenas colocar em ação diversas operações em momentos determinados, permanecendo nas questões técnicas, ou seja, limitando-se aos instrumentos avaliativos.

Emum primeiro olhar podemos enxergar que a avaliação tem uma relação de dependência frente a outras categorias; entretanto, com um olhar mais atento, percebemos que essa relação não se estabelece realmente, visto ser a avaliação que concretiza os objetivos; caso contrário eles seriam sempre uma abstração. As categorias objetivo/avaliação formam um par dialético que modula as relações do par conteúdo/método (FREITAS, 1995). Nesta direção, Escobar (1997, p.113) afirma que, tanto a avaliação quanto os objetivos estão dados pela "[...] natureza da organização do trabalho pedagógico, que reflete o projeto histórico hegemônico". A não observância das relações que se estabelecem entre estes pares no movimento do real, no âmbito escolar, faz com que as possíveis análises sejam construídas sem a percepção das contradições que se manifestam e se concretizam.

Os procedimentos de avaliação estão em estreita relação com a forma que a escola assume neste momento histórico, e que corresponde a funções tais como classificar, hierarquizar, controlar e construir os valores determinados pela sociedade, formando indivíduos submissos (FREITAS, 2003). Como nos declara Fernandes e Freitas (2007, p.04), "Em nossa sociedade, de um modo geral, ainda é bastante comum as pessoas entenderem que não se pode avaliar se os estudantes não receberem uma nota pela sua produção [...]", tendo o caráter quantitativo uma expressiva importância comparado aos elementos qualitativos. Este quadro fica evidente ao constatarmos que o principal instrumento avaliativo dos professores é a prova, sendo concretizada na forma de nota/ conceito/parecer e etc., gerando, assim, a classificação entre os estudantes a partir da divulgação "pública" das notas. Para que possamos construir novas formas de avaliar, será necessário repensar a escola como um todo. Não teremos outra avaliação nesta escola, da mesma forma que não teremos outra escola, com esta avaliação. Este é o elemento determinante do processo pedagógico por delimitar os aspectos instrucional, comportamental e de valores e atitudes, revelando os verdadeiros objetivos da escola, que nem sempre são proclamados. Nesta perspectiva, podemos afirmar que ela é a prática entre as práticas, tendo um caráter extremamente formativo, buscando homogeneizar os 
estudantes ao construir um instrumento avaliativo igual para toda uma turma, uma escola ou um conjunto de escolas de um país.

Instiga-nos pensar o que se ensina, ou o que se quer ensinar com as práticas avaliativas que se apresentam. Na busca por sanar tal questionamento, percebemos que a avaliação, em sala de aula, tem pelo menos três componentes que precisam ser considerados (FREITAS, 2003). Estes se manifestam nos aspectos: (1) instrucional; (2) comportamental; e de (3) valores e atitudes. O primeiro é aquele em que se avalia o domínio das habilidades e conteúdos a partir de provas, trabalhos, entre outros. Em grande parte das análises feitas no âmbito da avaliação captam somente esse elemento. O segundo componente é um potente instrumento de poder nas mãos dos professores, visto avaliar o comportamento dos alunos em sala de aula. Quem nunca ouviu frases como: "Pedrinho, se você não se sentar vou te tirar nota"; ou também para a turma em geral: "Se vocês não se comportarem, vou fazer prova". A avaliação cria uma estrutura de poder, estando o controle nas mãos do professor sobre o aluno. O terceiro elemento ocorre no dia a dia em sala de aula, e se concretiza em repressões e em exposições dos alunos. Consistem em comentários críticos e até humilhações frente à turma. Escobar (1997, p.115), em suas análises a respeito da categoria avaliação, observa que essa questão se expressa em um processo no qual os alunos sofrem "[...] a desconsideração das suas motivações, a repressão da sua espontaneidade, dos seus desejos e, com isso, uma pressão tendente a moldar e/ou mudar seus valores" por parte dos professores e, algumas vezes, por parte dos colegas. Para Freitas (2003, p.43), a articulação destes três componentes intrínsecos à avaliação "[...] cria o campo necessário para que se exercitem relações sociais de dominação e submissão ao professor e à ordem" capitalista por parte dos alunos.

A partir do exposto, entendemos existir na avaliação o campo formal e o informal, ou seja, ela ocorre nestes dois planos. No campo formal encontram-se as técnicas e os procedimentos (provas, questionários, trabalhos, pesquisas, etc.) aplicados pelos professores para um "fim" único: a nota individual do aluno. No campo informal estão os juízos de valor que, embora sejam "invisíveis", acabam por influenciar os resultados finais. Estas interações criam as representações dos professores sobre os alunos. Para Freitas (2003, p.45) “a parte mais dramática e relevante da avaliação se localiza aí, nos subterrâneos 
onde os juízos de valor ocorrem. Impenetráveis, eles regulam a relação professor-aluno e vice-versa". Esse conjunto de relações, que giram em torno do campo formal e informal, constrói os elementos que são "ensinados" a partir da avaliação, internalizando no conjunto dos estudantes a obediência às leis civis, a aceitação da posição de classe que lhes foi atribuída na hierarquia social, entre outros.

No Quadro 1, a seguir, apresentamos a imagem que ilustra nosso entendimento, segundo Freitas (2003, p.44).

QUADRO 1 - Ilustrativo do Sistema da Avaliação

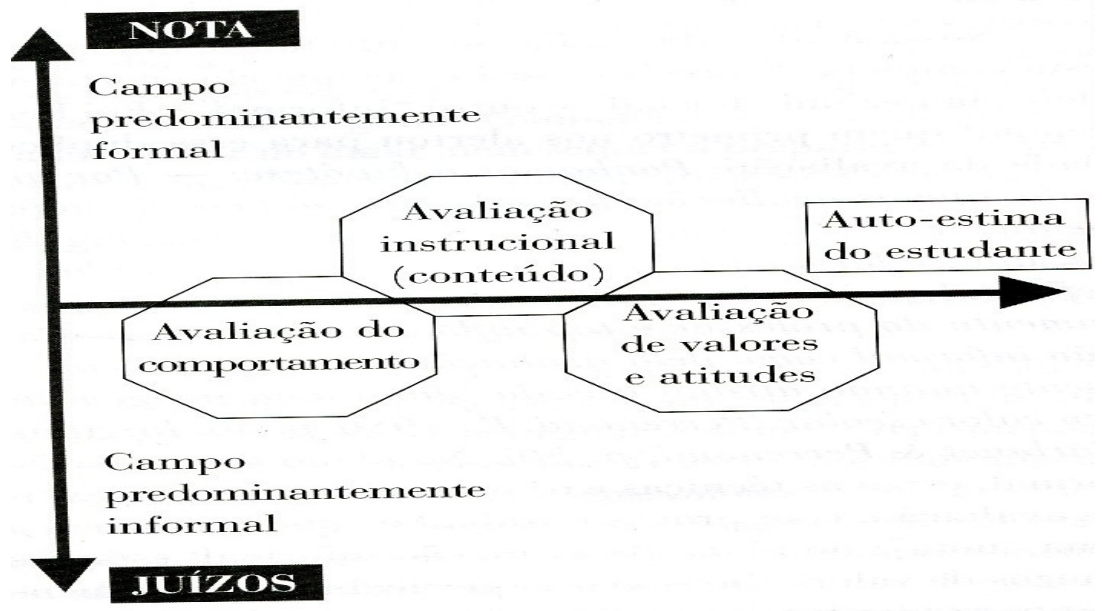

Quadro 1: relação construída a partir da mediação entre o campo formal e informal existente no processo avaliativo. (FONTE: Freitas, 2003, p.44)

A avaliação recolhe muito mais do que apenas evidências do processo de ensino, visto ser ela, possivelmente, a categoria decisiva para assegurar a função social que a escola detém na sociedade capitalista, para garantir os objetivos de reprodução do sistema capitalista. Entendemos a partir disto que também se ensina que nem todos são para escola, por mais que a escola seja para todos, enquanto discurso. Este discurso se constitui como um processo de legitimação pelo consenso em torno da sociabilidade burguesa, tendo na educação um grande instrumento para seu desenvolvimento (LIMA e MARTINS, 2005).

A partir desta questão, através de uma consulta a página do programa "Todos pela Educação" ${ }^{4}$, percebemos que o número de matrículas nos anos inicias do Ensino Fundamental, em 2011, era de 16.360.770 e, nos anos finais, de 13.997.870. Estendendo o olhar para o

4 Disponível em: http://www.todospelaeducacao.org.br/educacao-no-brasil/numeros-do-brasil/brasil/. Acessado em 24 de junho de 2013. 
Ensino Médio, percebemos uma grande variação visto que o número de matrículas é de apenas 8.400.689. Fica evidente a existência de uma considerável evasão escolar, sendo este um elemento, cuja análise se faz necessária e urgente. Obviamente que a avaliação não é a única responsável; entretanto, há uma considerável contribuição dela neste processo, sendo uma das determinações que se sintetiza no processo da evasão escolar.

Avaliando, ensina-se que não há espaço para todos na educação, na escola, no esporte, na ocupação de postos de trabalhos, entre outros. Avalia-se como se ensina a partir da seleção dos estudantes em distintos grupos, a partir da sua condição de classe e, dessa forma, também, se ensina como se avalia. Para Silva (2010), o reflexo de tais relações na escola e consequentemente na avaliação é a construção de um instrumento da ideologia hegemônica, pois a forma como esta se realiza nas escolas determina a separação este aqueles que farão parte da classe dominante e da classe dominada. Para Escobar (1997), a função 'objetivo' da avaliação é hierarquizar os alunos, estimulando a competição e distribuindo desigualmente as oportunidades escolares e sociais. Esta hierarquia é produzida pela avaliação, através de quatro pontos que, de acordo com Freitas (1995, p.242) se apresentam da seguinte forma;

(1). Manutenção propriamente dita das classes dominantes em profissões nobres; (2). Eliminação adiada, ou manutenção provisória das classes populares em profissões menos nobres; (3). Manutenção adiada, ou exclusão pura e simples das camadas populares do interior da escola, ou seja, a evasão; (4). Eliminação propriamente dita (privação), no sentido de impedir o ingresso das camadas populares na escola.

Percebemos que, nestas relações, ensina-se, conscientemente ou não, que a permanência no processo escolar e a futura ocupação de um posto de trabalho (nobre ou menos nobre) ocorrerão de acordo com a origem, i.e., a classe social do estudante. Ensina-se também que esse processo não é para todos; assim, segundo esta visão, a responsabilidade não é do sistema, e sim do indivíduo que não conseguiu se adequar às relações democráticas da sociabilidade burguesa. A partir desta perspectiva, como já apontamos, a avaliação apresenta um caráter extremamente formador. Concretiza-se uma relação em que há alguém que ensina e alguém que apreende; alguém que manda e alguém que obedece; alguém que avalia e alguém que é avaliado; uma relação professoraluno em que um detém o conhecimento e o outro, a ignorância. 
As relações de manutenção e eliminação que se estabelecem no interior da avaliação refletem a divisão social do trabalho na sociedade capitalista. Para visualizar a questão, tomamos como exemplo o Quadro 2, a seguir, que representa o esquema estabelecido por Freitas (1995, p.249) ${ }^{5}$.

Quadro 2 - llustrativo da Divisão Social do Trabalho

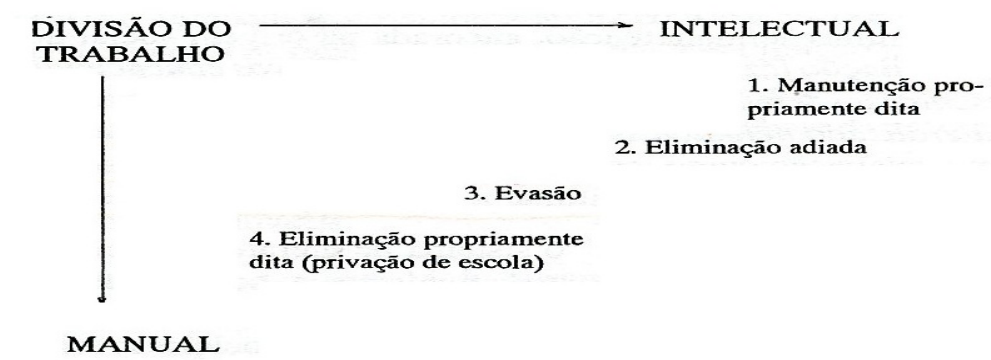

Quadro 2: divisão social do trabalho nas sociedades capitalistas. FONTE: Freitas, 1995, p.249.

Frente a tais apontamentos, apresenta-se a questão da relação entre os pares dialéticos, visto que estes (objetivo/avaliação, conteúdo/método) requererem um olhar atento. O par objetivo/ avaliação determina as relações do par conteúdo/ método visto que a "objetivação da função da escola [...] se dá no interior de seu conteúdo/ método" (FREITAS, 1995, p.97). Essa relação se estabelece pelo fato de a avaliação concretizar os objetivos, ou seja, a avaliação determina os objetivos, ao mesmo tempo em que é determinada por eles, estabelecendo uma relação dialética. A partir da construção dos objetivos, e estabelecidos os critérios da avaliação, definimos a forma como construiremos ao longo do processo letivo a relação de ensino-aprendizagem; dessa forma, portanto, entendemos que a avaliação é que determina o método (ensino).

Manifestamos nosso posicionamento de que não podemos desvincular da educação as relações sociais que se desenvolvem para além da escola. Em outras palavras, para construirmos uma análise clara da categoria avaliação não podemos analisá-la por ela mesma, sem as devidas considerações a respeito do movimento existente entre os pares dialéticos objetivos/avaliação, conteúdo/método, e os demais determinantes existentes na relação ensino-aprendizagem que decorrem do modelo ideológico definidor dos modos de produção capitalista.

${ }^{5}$ De acordo com Freitas (1995), este quadro reflete uma possibilidade do desenvolvimento da luta de classes no interior da escola. 


\section{Considerações Finais}

Acreditamos que o debate, a contraposição de ideias, compreensões, é um exercício necessário para que possamos avançar na busca por novas possibilidades de mediação com o conhecimento. Cabe ressaltar que nosso entendimento a respeito da temática "é" um constante processo frento a continuidade de nossos estudos. As discussões no meio acadêmico que perpassam a análise da categoria avaliação não cabem, em sua totalidade, neste trabalho, assim como, não cabe, da mesma forma, nossa compreensão frente as múltiplas determinações existentes nesta categoria. Entretanto, é importante ressaltar que este acúmulo resulta em importante exercício teórico no sentido de ampliar as discussões frente este tema tão importante para nossa atividade prática, no chão da escola, entre outros espaços.

A análise do processo histórico centrado no campo educacional se faz necessária para que possamos compreender, a partir de uma determinada perspectiva teórica, os determinantes que se fizeram presentes na construção da escola enquanto instituição social eleita para a instrumentalização do conjunto da sociedade civil. Este exame nos permite compreender que o formato que a escola assume é um reflexo da luta de classe, pendendo para os interesses burgueses em detrimento dos interesses dos trabalhadores.

A centralidade assumida pela categoria avaliação na organização do trabalho pedagógico é de fundamental compreensão, visto que a forma que ela assume reflete, também, os interesses de classe. Para, além disso, seu caráter pedagógico se coloca à frente de sua função meramente avaliativa, visto que ela ensina o lugar de cada estudante na hierarquia social.

Entendemos que as formulações apontadas por Freitas (1995), estão corretas. A relação estabelecida entre o singular (avaliação) e o geral (modo de produção capitalista), mediados pelo particular (escola), é vital para a construção de uma análise concreta da realidade. A formulação das relações de manutenção e eliminação demonstra a preocupação de não perder de vista o movimento existente entre a teoria e a prática.

Por fim, apontamos nosso interesse de que o exame desta categoria seja aprofundado pela comunidade acadêmica, mediante a centralidade que ocupa no movimento existente na organização do trabalho pedagógico, assim como a necessidade de uma real compreensão desse movimento, a fim de instrumentalizar nossa prática. 


\section{Referências}

ENGUITA, Mariano Fernández. A face oculta da escola: educação e trabalho no capitalismo. Porto Alegre: Artes Médicas, 1989.

ESCOBAR, Michele Ortega. Transformação da didática: construção da teoria pedagógica como categorias da prática: experiência na disciplina escolar educação física. Tese de Doutoramento em Educação, Departamento de Educação, Universidade Estadual de Campinas, 1997.

FERNANDES, Cláudia de Oliveira; FREITAS, Luiz Carlos de. Indagações sobre currículo: currículo e avaliação. Brasília: Ministério da Educação, Secretaria de Educação Básica, 2007.

FREITAS, Luiz Carlos de. A Escola Única do Trabalho: explorando os caminhos de sua construção. In. Roseli Salete CALDART (Org.). Caminhos para transformação da escola: reflexões desde práticas da licenciatura em educação do campo. São Paulo: Expressão Popular, 2010, p.155-175.

FREITAS, Luiz Carlos de. Ciclos, seriação e avaliação: confronto de lógicas. São Paulo: Moderna, 2003.

FREITAS, Luiz Carlos de. Crítica da organização do trabalho pedagógico e da didática. São Paulo: Moderna, 2003.

FREITAS, Luiz Carlos de. Crítica da organização do trabalho pedagógico e da didática. São Paulo: Campinas (SP): Papirus, 1995.

FRIZZO, Giovanni Felipe Ernest. A organização do trabalho pedagógico na escola capitalista. Tese de Doutoramento em Educação Física, Departamento de Educação Física, Universidade Federal do Rio Grande do Sul, 2012.

FRIZZO, Giovanni Felipe Ernest. Trabalho pedagógico: conceito central no trato do conhecimento da pesquisa em educação. Trabalho Necessário (Online), v.6, p.01-29, 2008.

LIMA, Kátia Regina de Souza; MARTINS, André Silva. Pressupostos, princípios e estratégias. In: Lucia MARTINS, Wanderley NEVES (org.). A nova pedagogia da hegemonia: estratégias do capital para educar o consenso. São Paulo: Xamã, 2005, p.43-67. 
LIMA, Marcos Antonio Martins. Pantometria, psicometria, docimologia e avaliação científica: uma trajetória histórica para a avaliação educacional até a era contemporânea. In: Marcos Antonio Martins LIMA e Marcos MARINELLI (Orgs.). Epistemologias e metodologias para a avaliação educacional: múltiplas visões e abordagens. Fortaleza: UFC, 2010, p.83-126.

LUKÁCS, Georg. Introdução a uma estética marxista. (tradução de Carlos Nelson Coutinho e Leandro Konder). Rio de Janeiro: Civilização Brasileira, 1968.

MACHADO, Nílson José. Educação: projetos e valores. São Paulo: Escrituras, 2000.

MARX, Karl. O 18 Brumário de Luiz Bonaparte. (tradução de Nélio Schneider). São Paulo: Centauro, 2003.

MARX, Karl e ENGELS, Friedrich. A ideologia alemã. (tradução de Álvaro Pina). São Paulo: Expressão Popular, 2009.

PISTRAK, Moisey Mikhaylovich. Fundamentos da Escola do Trabalho. (tradução de Luiz Carlos de Freitas). São Paulo: Expressão Popular, 2000.

PISTRAK, Moisey Mikhaylovich (Org.). A Escola-comuna. (tradução de Daniel Aarão Reis Filho). São Paulo: Expressão Popular, 2009.

ROZENGARDT, Rodolfo. Verbetes “Avaliação”, p.40-44; “conteúdo”, p.94-97. In: Fernando Jaime GONZÁLEZ e Paulo Evaldo FENSTERSEIFER (Orgs.). Dicionário crítico de educação física. 2ed. ljuí (SC): Unijuí, 2008.

SILVA, Alcir Horácio da. A organização do trabalho pedagógico e a avaliação da aprendizagem na educação física no Colégio de Aplicação da UFG. Tese de Doutoramento em Educação, Departamento de Educação, Universidade Federal da Bahia, 2010.

TAFFAREL, Celi Neuza Zulke. Do trabalho em geral ao trabalho pedagógico: contribuição ao debate sobre o trabalho pedagógico na educação física. Revista Motrivivência. Ano XXII, n. ${ }^{\circ} 35$, p.18-40, dez./2010. 


\section{Evaluación cómo Categoría: Elementos hacia una Discusión}

RESUMEN: El objetivo de este estudio es establecer reflexiones sobre la organización del trabajo pedagógico, centrando la atención en el movimiento entre los pares dialécticos "objetivo-evaluación" y "contenido-método" para acentuar la importancia de la categoría evaluación. Para fundamentar los argumentos, se ha hecho un examen de las pruebas relacionadas con el desarrollo del proceso histórico, sobre todo en el campo educativo. Creemos que es necesario profundizar en el análisis de esta categoría, por lo que podemos, entre otras cosas, dotar a la práctica pedagógica.

Palabras clave: Evaluación. Educación Física. Escuela. Organización del Trabajo Pedagógico.

\section{Evaluation how Category: Elements toward a Discussion}

ABSTRACT: The aim of this study is to establish reflections on the organization of educational work, focusing on the movement between dialectical pairs "target-evaluation" and "content-method" to emphasize the importance of the category evaluating. In support of the arguments, it has been a review of the evidence relating to the development of the historical process, especially in the educational field. We believe it is necessary to deepen the analysis of this category, so we can, among other things, provide pedagogical practice.

Keywords: Evaluation. Pedagogical Labour Organization. Physical Education. School. 